OPEN ACCESS

Edited by:

Jeffrey A. Riffell,

University of Washington,

United States

Reviewed by:

Evan Fricke,

National Socio-Environmental

Synthesis Center (SESYNC),

United States

Greg Pask,

Bucknell University, United States

${ }^{*}$ Correspondence: Radhika Venkatesan

radhika@ncbs.res.in

Specialty section: This article was submitted to

Chemical Ecology,

a section of the journal

Frontiers in Ecology and Evolution

Received: 06 February 2019 Accepted: 13 June 2019

Published: 28 June 2019

Citation:

Sasidharan $R$ and Venkatesan $R$ (2019) Seed Elaiosome Mediates

Dispersal by Ants and Impacts Germination in Ricinus communis.

Front. Ecol. Evol. 7:246

doi: 10.3389/fevo.2019.00246

\section{Seed Elaiosome Mediates Dispersal by Ants and Impacts Germination in Ricinus communis}

\author{
Rohit Sasidharan and Radhika Venkatesan* \\ National Centre for Biological Sciences, Tata Institute of Fundamental Research, GKVK, Bengaluru, India
}

Myrmecochory is the ant-mediated secondary dispersal of seeds that depends on the presence of a lipid-rich seed appendage known as "elaiosome." Attractive cues of elaiosomes that drive such an interaction and benefits to the plant are not clearly understood. Here, using Ricinus communis, we establish reward compositions and determine the benefits of myrmecochory to the plant. We also compare elaiosome compositions across ecotypes. Our results show that the elaiosome is essential for seed displacement and olfactory cues are important attractive cues. Nonanal and 2-decenal were found to be the major attractive volatiles in the castor elaiosome. Different ant species showed different behaviors toward elaiosome-bearing seeds. Among them, Pheidole grayi was efficient in dispersal but did not disperse all seed ecotypes tested. Major differences in fatty acid levels were observed between ecotypes. To determine the benefits of myrmecochory, germination rates before and after removal of elaiosome were studied. Seed germination improved upon elaiosome removal and aqueous elaiosome extract inhibited germination indicating water-soluble inhibitory factors. Further, ant nest sites were richer in nitrogen than control sites, revealing a clear benefit of seed displacement. In summary, we demonstrate the ecological significance of the seed elaiosomes in the absence of nutritive rewards for seed dispersers.

Keywords: elaiosome, myrmecochory, plant-ant interactions, Ricinus communis, seed dispersal, seed germination

\section{INTRODUCTION}

Plants, being sessile, face the challenge of seed dispersal. Efficient seed dispersal allows plants to colonize new habitats, increase the probability of seedling establishment and escape predators. Dispersal could involve a primary mechanism and/or a secondary mechanism, where seeds are moved after an initial dispersal event. Myrmecochory refers to secondary seed dispersal involving ants that are attracted to lipid-rich bodies called "elaiosomes" on the seeds (Vander Wall et al., 2005). Ants carry elaiosome-bearing seeds commonly known as "diaspores" to their nest, thus causing seed displacement. Inside the nest, the elaiosome is removed, fed to larvae, and the bare seed is discarded into a refuse pile inside or outside the nest (Servigne and Detrain, 2008). The elaiosome occurs in over 11,000 plant species across 77 angiosperm families and is hypothesized to have arisen from over 100 independent evolutionary origins. It is generally fleshy and edible to ants, yet diverse in color, shape, and size (Lengyel et al., 2010). In contrast to most vertebrate-dispersed fruits, elaiosome-bearing seeds tend to lack prominent fleshy pericarps. Their functional difference is reflected in a divergent nutrient composition with elaiosomes tending to be higher in nitrogen 
levels while fleshy pericarps are usually higher in potassium (Hughes et al., 1994). Chemical cues in the elaiosome elicit seed-carrying behavior in ants. For instance, elaiosomes from taxonomically diverse seeds were shown to contain 1,2-diolein or oleic acid, which elicit seed-carrying behavior when applied to dummy seeds (Fischer et al., 2007). Pfeiffer et al. (2009) also showed that free oleic acid was the only compound that differed between diaspores removed at low and high rates. However, the attractive cues of elaiosome and its role in germination are largely unclear. Also, intra-generic variation in elaiosome composition and attraction is unexplored.

For plants, pollinators and seed dispersers are essential to their diversification and colonization of new habitats (Crane et al., 1995). Myrmecochorous dispersal allows plants to expand their dispersal area, reducing competition, and increasing success of progeny and it is a reliable means of seed propagation (Leal et al., 2013). Dispersal interactions are complemented by other beneficial interactions with ants, for instance, ants using extrafloral nectar produced by many plants as a critical food source, which in turn protects the plants from herbivory, and predators (Trager et al., 2010). However, not all ant species that feed on the elaiosome play a role in seed dispersal. Some, such as Solenopsis spp., remove the elaiosome on-site without displacing the seed (Leal et al., 2007). Plant traits such as elaiosome size and chemistry, as well as the timing, spatial pattern, and volume of seed release, could allow plants to specifically associate with certain ants and avoid cheaters (Giladi, 2006). The diversity within elaiosome chemistry and attraction has not been wellexplored intra-specifically though it has been compared intragenerically (Lanza et al., 1992). Here, we address this knowledge gap by investigating the detailed composition of the elaiosome and its role in shaping ant interactions. Since fatty acids are key components of the lipid-rich elaiosome, we investigated their variability across geographically separated ecotypes. Further, we extended the search toward variability in compositions of volatiles as well as sugars.

Ricinus communis (castor) seeds carry a prominent elaiosome and lack attractive, fleshy rewards. The plant occurs worldwide as a colonizing species and is mainly cultivated for the oilrich seeds. The fruits are three-carpellate and show explosive, ballistic dispersal upon ripening, scattering the seeds found individually within a carpel (Martins et al., 2006). The castor plant also bears extra-floral nectar at the base of petioles and inflorescence axes, attracting ants that defend them (Heslin et al., 2013). Myrmecochory is the only form of secondary dispersal reported in castor and is known to increase dispersal distances of seeds released from the fruit (Martins et al., 2006). The chemical cues involved in this interaction are largely uncharacterized and the role of elaiosome in germination has been studied with mixed results (Severino et al., 2012; Msaakpa et al., 2013). Here, we studied the role of elaiosome composition and its cues, asking how the presence of such lipid-rich appendages can play a role in plant success within a dispersed ecotype. We tested the hypotheses that (i) elaiosome is essential to seed dispersal by ants (ii) chemical composition of the elaiosome provides the basis for its attractiveness toward ants and (iii) elaiosome chemistry mediates processes that ensure plant fitness.
To test these, we performed field studies to assess ant dispersal of diaspores with and without elaiosomes. We also compared dispersal among various castor ecotypes. Using olfactometry assays, the role of volatile cues was determined. The chemical composition of elaiosomes was estimated and compared among ecotypes. Further, we investigated the impact of elaiosome on plant germination and found that it contains soluble factors that inhibit germination. Taken together, a comprehensive chemical investigation of the elaiosomes is reported underscoring its significance in seed dispersal and germination.

\section{MATERIALS AND METHODS}

\section{Study Site, Sampling, and Seed Removal Studies}

All studies were carried out in an $80 \times 60 \mathrm{~m}$ plot named "Mandara" (Ecotype I) (13.09253873 N, 77.57554573 E) between September-November 2017, with predominantly red soil and semi-arid climate. The plot is marked with large patches of $R$. communis plants scattered throughout the area. Diaspores from four other ecotypes namely Coimbatore (Ecotype II) $\left(10.95530036^{\circ} \mathrm{N}, \quad 76.94781132^{\circ} \mathrm{E}\right), \quad \mathrm{DCH}-4 \quad$ (Ecotype III), Guwahati (Ecotype IV) $\left(26.18333333^{\circ} \mathrm{N}, 91.69611111^{\circ} \mathrm{E}\right)$, and Pune (Ecotype V) $\left(18.53750000^{\circ} \mathrm{N}, 73.78916667^{\circ} \mathrm{E}\right)$ were studied (Figure 2B). While I, II, IV, and V are wild varieties from diverse geographical habitats across India, III is a commonly cultivated variety in India. For ant identification, 50 ant baits were set up throughout Mandara. Bait composition was modified from the Bhatkar diet (Bhatkar and Whitcomb, 1970) and consisted of: 1 egg, $62 \mathrm{~mL}$ honey, $5 \mathrm{~g}$ agar in $500 \mathrm{~mL}$ water. $10 \mathrm{~mL}$ of this mixture was poured into $15 \mathrm{~mL}$ falcon tubes which were then laid obliquely to form slants. 50 baits were laid across the field site randomly.

Five diaspores (D) bearing elaiosomes were placed alongside five seeds, from which elaiosomes were mechanically detached by hand, (MD) about $10 \mathrm{~cm}$ apart from an ant nest entrance. In some cases, elaiosomes (E) were alone placed near the nest to assess removal without seeds. Removal was assessed after $12 \mathrm{~h}$.

\section{Olfactometry Studies}

Y-tube olfactometry was used to evaluate the role of volatile cues in attracting ants to diaspores. Ecotype I diaspores were used to study this behavior. A glass Y-tube olfactometer was placed in a dark room at $25^{\circ} \mathrm{C}$ and behavior of $P$. grayi was recorded under red light. Air was pumped at a continuous flow rate of $20 \mathrm{ml} / \mathrm{min}$ at both ends. $0.3 \mathrm{~g}$ of the diaspore was placed inside the glass adapter with a thin mesh of cotton and the mesh alone served as control. For elaiosome extract, $100 \mu \mathrm{L}$ of dichloromethane extract $(0.4 \mathrm{mg} / \mu \mathrm{L})$ was loaded onto a Whatman filter paper and placed in a cut pipette tip fitted between airflow tubing and glass adapter. For testing individual volatiles, 1 ug of the compound (Sigma-Aldrich) dissolved in dichloromethane was loaded onto a Whatman filter paper and placed in a cut pipette tip in a similar manner. Solvent control was also similarly loaded. Individual foraging ants of $P$. grayi were introduced using a hollow connector glass tube. Ant choice was recorded within $5 \mathrm{~min}$. 


\section{Compositional Analysis of Elaiosome}

Elaiosome composition was studied to determine the chemical factors associated with seed dispersal and their variation across different ecotypes. To $0.2 \mathrm{~g}$ of homogenized elaiosome, $2 \mathrm{~mL}$ of dichloromethane containing 75 ppt dodecane (internal standard, Sigma-Aldrich) was added. The mixture was filtered through a $0.2 \mu \mathrm{m}$ cellulose acetate filter and concentrated. Analyses were performed on a 7000 Series Agilent GC equipped with MS as detector and an HP-5MS column $(30 \mathrm{~m} \times 250 \mathrm{um} \times$ $0.25 \mathrm{um}$, Agilent). Operating conditions: injector and detector temperature: $280^{\circ} \mathrm{C}$; He carrier gas flow rate: $1.1 \mathrm{ml} / \mathrm{min}$; oven temperature ramp starting from $60^{\circ} \mathrm{C}(1 \mathrm{~min})$ with programmed increases $\left(60-150^{\circ} \mathrm{C}\right.$ at $5^{\circ} \mathrm{C} / \mathrm{min}$, held for $5 \mathrm{~min}, 150-240^{\circ} \mathrm{C}$ at $20^{\circ} \mathrm{C} / \mathrm{min}, 240-250^{\circ} \mathrm{C}$ at $10^{\circ} \mathrm{C} / \mathrm{min}, 250-280^{\circ} \mathrm{C}$ at $15^{\circ} \mathrm{C} / \mathrm{min}$ and held for $2 \mathrm{~min}$ ). $1 \mu \mathrm{L}$ of sample solution was injected at a split ratio of 20:1.

Fatty acids were analyzed using the FAME (fatty acids methyl esters) method of trans-methylation using $10 \% \mathrm{BF}_{3}-\mathrm{CH}_{3} \mathrm{OH}$ as per Boieiro et al. (2012), using nonadecanoic acid (SigmaAldrich) as internal standard. Analyses were performed using similar operating conditions as above except for the temperature program which was set at $80^{\circ} \mathrm{C}$ for $2 \mathrm{~min}$ with programmed increases $\left(80-120^{\circ} \mathrm{C}\right.$ at $30^{\circ} \mathrm{C} / \mathrm{min}, 120-200^{\circ} \mathrm{C}$ at $4^{\circ} \mathrm{C} / \mathrm{min}$, held for $4 \mathrm{~min}, 200-240^{\circ} \mathrm{C}$ at $5^{\circ} \mathrm{C} / \mathrm{min}$, and held for $5 \mathrm{~min}$ ). $1 \mu \mathrm{L}$ of the solution was injected in split mode, at a split ratio of 40:1.

For sugar analysis, the sample was derivatized using MSTFA and analyzed by GCMS as per Fischer et al. (2007), using Larabinose and D-sorbitol (Sigma-Aldrich) as internal standards for sugars and sugar alcohols, respectively. Analyses were performed as above except for the temperature program, which was held at $65^{\circ} \mathrm{C}$ for $4 \mathrm{~min}$ with programmed increases (65$150^{\circ} \mathrm{C}$ at $25^{\circ} \mathrm{C} / \mathrm{min}, 150-180^{\circ} \mathrm{C}$ at $20^{\circ} \mathrm{C} / \mathrm{min}$, held for $2 \mathrm{~min}$, $180-200^{\circ} \mathrm{C}$ at $5^{\circ} \mathrm{C} / \mathrm{min}, 200-280^{\circ} \mathrm{C}$ at $20^{\circ} \mathrm{C} / \mathrm{min}, 280-320^{\circ} \mathrm{C}$ at $15^{\circ} \mathrm{C} / \mathrm{min}$ and held for $20 \mathrm{~min}$ ). $1 \mu \mathrm{L}$ of the solution was injected in split mode (4:1). In all analyses, identity of compounds was determined by matching the mass spectra with library database (NIST/EPA/NIH Mass Spectral Library, Ver. 2.2, 2014). Additionally, standard compounds (Sigma-Aldrich) were also analyzed using the same method to confirm the identity of the analytes using retention times as well as MS spectra.

\section{Soil Analysis}

In order to understand the impact of seed dispersal on plant fitness, soil nutrient composition of the dispersal sites was evaluated and compared with that of randomly sampled sites. Soil samples were collected from $\sim 5 \mathrm{~cm}$ depth from the sampling site. Analysis was performed on a CHN Elemental Analyser (LECO Corporation) using $20 \mathrm{mg}$ of the soil sample, which was filtered through a $0.2 \mathrm{~mm}$ pore-size sieve and baked at $80^{\circ} \mathrm{C}$ for $12 \mathrm{~h}$ overnight prior to analysis. Carbon, nitrogen and hydrogen were recorded as percentage by mass of total soil sample.

\section{Germination Studies}

Germination studies were carried out to determine if the elaiosome had an impact on seed dormancy. $2.5 \mathrm{~g}$ of the crushed elaiosome in $180 \mathrm{~mL}$ of MS-grade water was allowed to stand for $4 \mathrm{~h}$ and centrifuged at $8,000 \mathrm{rpm}\left(4^{\circ} \mathrm{C}\right.$ for $\left.30 \mathrm{~min}\right)$ followed by filtration through $0.2 \mu \mathrm{m}$ nylon filter. $2 \mathrm{~mL}$ of this extract was added to Ecotype I seeds in polystyrene wells of $2.5 \times 2.5 \mathrm{~cm}$ area and $4 \mathrm{~cm}$ depth covered with coco peat. Similarly, water was added to controls. Germination was recorded after 15 days based on hypocotyl emergence from soil. Germination percentage was recorded as $\%$ germination $=$ number of seeds germinated/total no. of seeds $\times 100$. The experiment was conducted similarly with $A$. thaliana Col-0 seeds, but in sterile 48 -well plates without coco peat as germination medium. Tests were performed in controlled greenhouse conditions $\left(12 \mathrm{~h}\right.$ day/ $12 \mathrm{~h}$ night, $30^{\circ} \mathrm{C}$ and RH: 55-60\%).

\section{Statistical Analyses}

A majority of the data were analyzed by one-way ANOVA using Tukey's or Bonferroni's post-hoc test to identify between-group differences. For the seed removal studies, elaiosome was taken as the independent variable to observe its effect on removal rate, the dependent variable. For compositional studies, ecotype was taken as the independent variable with individual volatile, fatty acid, or sugar concentration as the dependent variable. For the studies on soil composition, carbon and nitrogen levels were taken as dependent variables varying between different soil samples. For germination studies, elaiosome was taken as the independent variable to observe its effect on germination rate, the dependent variable. For Y-tube experiments, two-sided binomial test was used to test significant differences between the two different treatments. All statistical analyses were performed using GraphPad Version (Prism) as well as Microsoft Excel.

\section{RESULTS}

\section{Seed Removal by Ants}

From a total of 50 baits that were laid by random sampling, 29 were recovered with ants. Based on their incidence across the field site, their relative abundances were estimated. The ant species were identified as Leptogenys processionalis, Monomorium indicum, Solenopsis geminata, Camponotus compressus, P. grayi, and Aphaenogaster beccarii. A single count of Monomorium pharaonis was also observed (Table S1). Solenopsis geminata ants removed the elaiosome on-site without transporting the seed to the nest, a behavior similar to diaspore "cleaning" (Leal et al., 2007), while Aphaenogaster and Pheidole ants actually dispersed the seeds by transporting them to the nest. We did not observe other ants being attracted to diaspores that were "cleaned." Elaiosome-removal behavior thus varied across ant species; with highest dispersal rates in P. grayi followed by $A$. beccarrii ants while $S$. geminata were mainly involved in onsite removal of elaiosome, without displacing the seed (Figure 1). P. grayi was our focal species for further studies as it was also the largest population of seed dispersers in our field site. Ants of P. grayi rapidly discovered diaspores or elaiosomes placed near the nest entrance (Figure 2A). Diaspores were significantly dispersed over seeds where elaiosomes where mechanically detached (MD). Elaiosomes were also removed compared to MD seeds. Removal rates of the elaiosome after $24 \mathrm{~h}$ in randomly sampled sites 1, 2, and 3 were observed to be 79.54, 88.6, and 97, respectively (Figure S1, Supplementary Information Methods). 


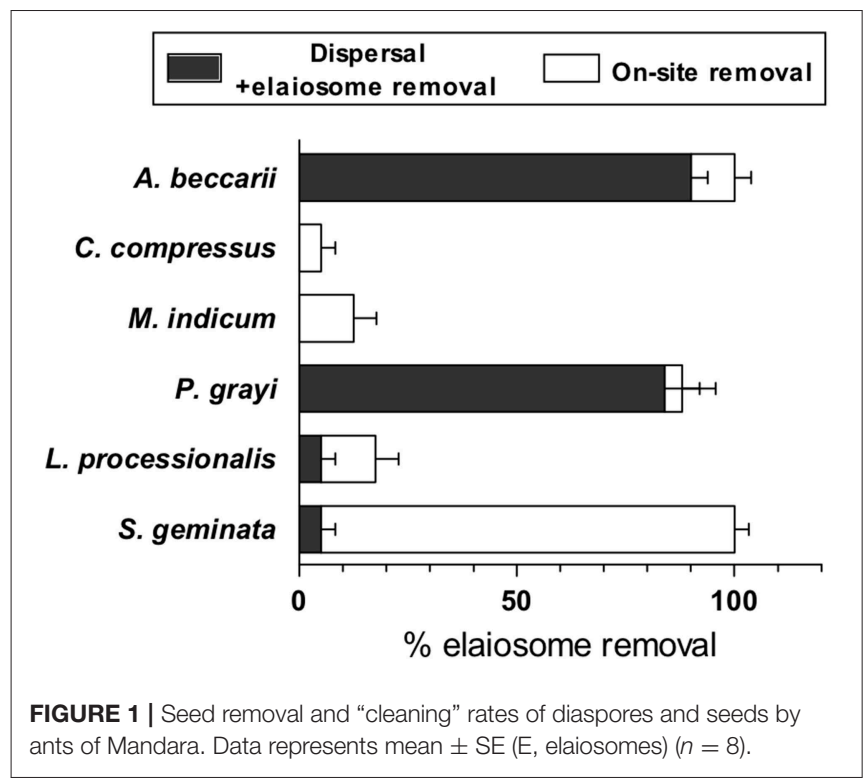

Interestingly, seed dispersal rates by $P$. grayi varied across ecotypes (Figure 2C) and except for ecotype III, other seeds were equally removed.

\section{Cues in Seed Dispersal}

P. grayi ants were more attracted toward diaspore volatiles compared to controls in the olfactometer assay (Figure 3A). Interestingly, no significant difference was observed between diaspore and seeds. The dichloromethane extracts of both seeds and elaiosomes were more attractive than the solvent blank (Figure 3A). GCMS analysis of the extracts revealed two major volatiles, 2-decenal, and nonanal (Figure 3B). Their levels varied across varieties. All ecotypes tested had higher levels of 2-decenal on average. Ecotype V, showed significantly higher levels of 2decenal than the others $\left(3.4 \pm 0.2 \mathrm{ug} \mathrm{g}^{-1} \mathrm{FW}\right)$. Both these volatiles were also found to be attractive to $P$. grayi ants in the olfactometer assay (Figure 3A).

\section{Elaiosome Composition}

FAME analysis of elaiosomes revealed presence of saturated (Saturated fatty acids- SFAs) or unsaturated (UFAs) chains with 14 to $18 \mathrm{C}$ units. Palmitic acid, oleic acid, linoleic acid, stearic acid, myristic acid, and palmitoleic acid were found to be the major fatty acids in the elaiosome accounting for about 93.499\% of the total fatty acids (Figure 4). Elaiosome compositions differed across ecotypes in quantities of both SFAs and UFAs. Overall fatty acid compositions were highest in ecotypes II and IV, followed by ecotype I and IV, respectively. Elaiosomes of ecotype III showed significantly lower levels of the major fatty acids (Figure 4). Palmitic acid was found to be the highest in all ecotypes, followed by oleic acid as the second highest fatty acid, except in the case of III, where stearic acid was the second highest fatty acid. Ecotype III had a lower total fatty acid concentration as well as lower proportions of UFAs:SFAs.

Sugar analysis showed that several sugars and sugar alcohols were present in the elaiosomes ranging upto $10 \mathrm{mg} \mathrm{g}^{-1} \mathrm{FW}$. The
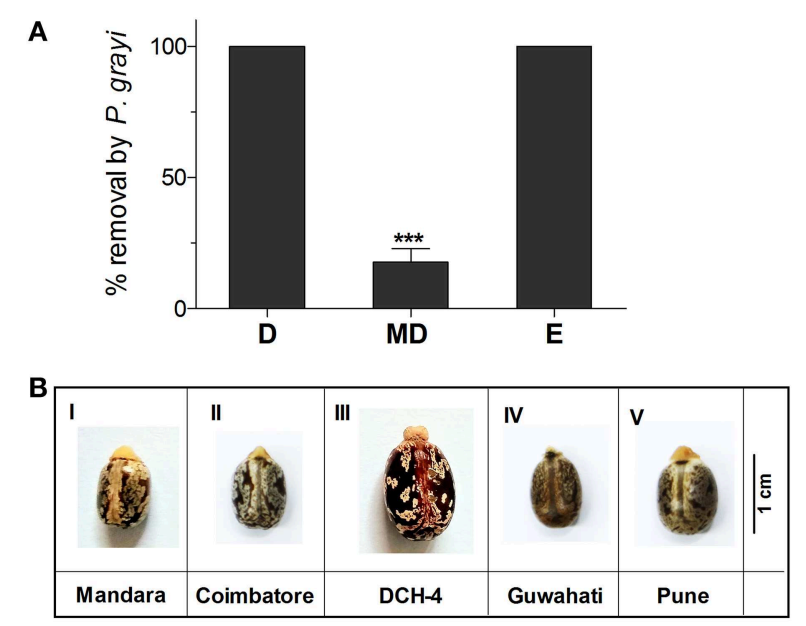

C

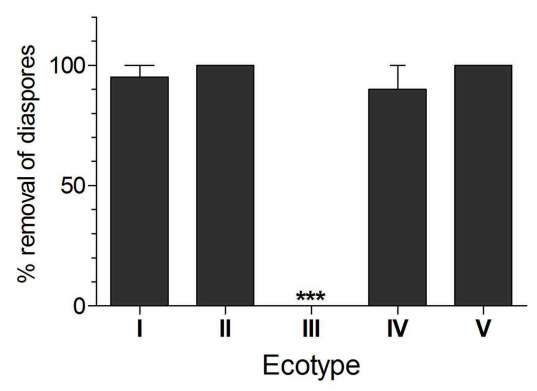

FIGURE 2 | (A) Removal rates of diaspores, seeds and elaiosomes of "Mandara" variety by $P$. grayi. Data represents mean \pm SE. Asterisk indicates significant difference between treatments tested using Tukey's post-hoc test after one-way ANOVA ( $p \leq 0.01, n=9$ ) (D, Diaspores; MD, manually detached seeds; E, elaiosomes). (B) Ecotypes used for testing differences in dispersal (C). Removal rates of diaspores of different ecotypes of $R$. communis. Data represents mean $\pm \mathrm{SE}$. Asterisk indicates significant difference between treatments tested using Tukey's post-hoc tested after one-way ANOVA $(p \leq 0.01, n=4)$.

major sugars identified were glucose, rhamnose, ribose, sucrose, and trehalose while the major sugar alcohols included myoinositol, glycerol, mannitol, and arabitol (Figure 5). The most important differences between ecotypes were seen in sucrose, which was absent in ecotypes I, III, and IV, and mannitol, which was significantly higher in ecotype IV $\left(11.0 \pm 2.8 \mathrm{mg} \mathrm{g}^{-1} \mathrm{FW}\right)$. Unlike fatty acids, ecotype III had equivalent amount of total sugars and sugar alcohols as dispersed ecotypes.

\section{Elaiosome and Seed Germination}

Soil around the ant discard site showed higher levels of carbon and nitrogen than that of randomly sampled points in the field site as well as areas where plants were already growing (Figure 6A). Germination rates were higher in both $\mathrm{AD}$ and $\mathrm{MD}$ seeds under laboratory conditions (Figure 6B). Interestingly, no significant difference in water imbibition (Supplementary Information Methods) was observed between diaspores, $\mathrm{AD}$ and $\mathrm{MD}$ seeds (Figure S2A). When simple wax was used as an elaiosome mimic (described in 


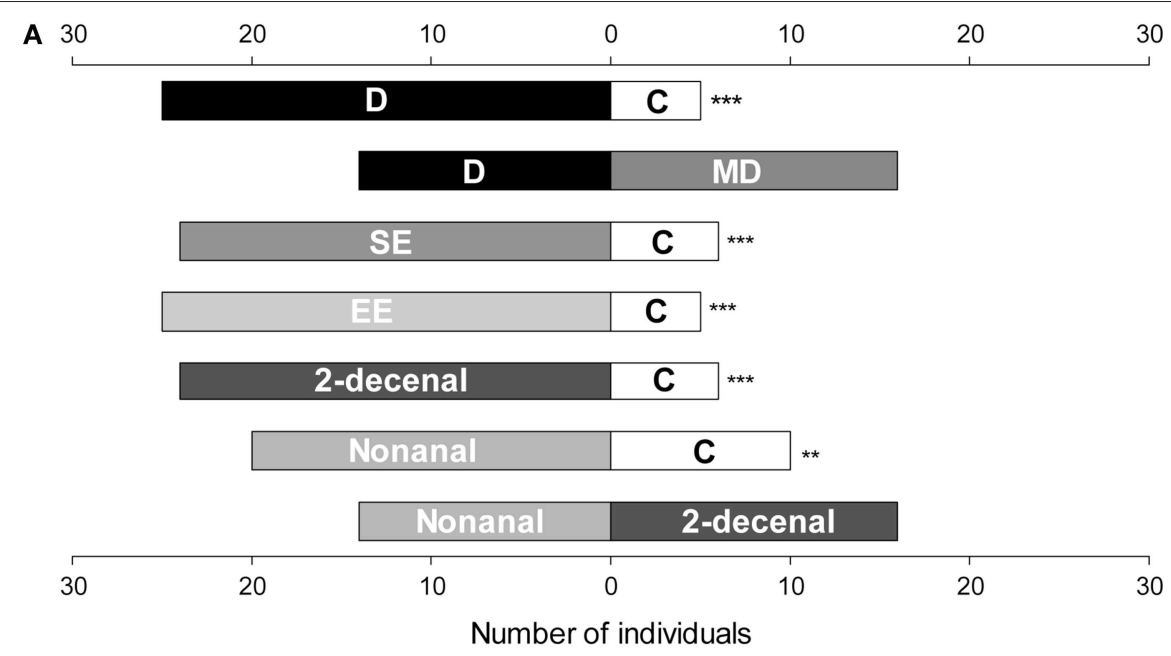

B

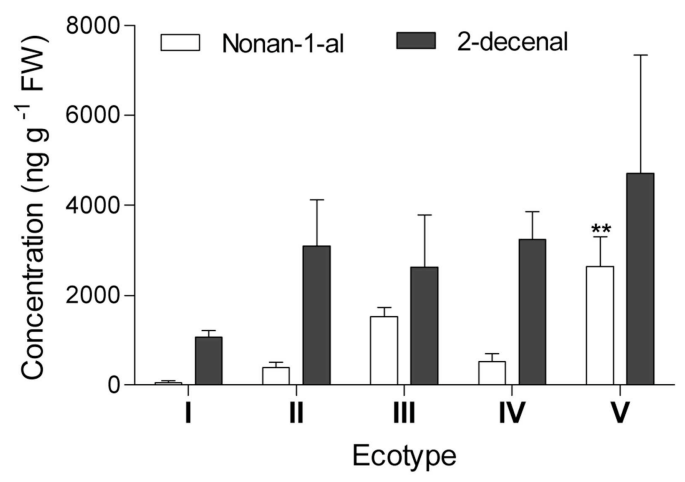

FIGURE 3 | (A) Y-tube olfactometry assay. Results are presented as binary choices between treatments. Asterisk indicates significant difference between treatments using two-sided binomial test $(p \leq 0.001, n=30)$ (D, Diaspores; MD, manually detached seeds; SE, seed extract; EE, elaiosome extract; C, control). (B) Composition of dichloromethane extracts of $R$. communis elaiosomes. Data represent mean $\pm \mathrm{SE}$ of the concentration $\left(\mathrm{mg} \mathrm{g}^{-1} \mathrm{FW}\right)$ measured using GCMS analysis. Asterisk indicates significant differences in individual volatile concentrations between varieties, tested using Bonferroni's post-hoc test after one-way ANOVA $(p \leq 0.01, n=3$ ).

Supplementary Information Methods), diaspores showed lower germination rates compared to wax-mimics (Figure S2C), suggesting that elaiosomes do not necessarily act as physical barriers to germination. It was also observed that diaspores as well as $\mathrm{AD}$ seeds developed fungal attack faster than MD seeds (Figure S2B, Supplementary Information Methods). Fungal attack could play a role in eventual breakdown of the elaiosome though it is unclear if it has any effect on germination.

Incubation with aqueous elaiosome extract (EE) inhibited germination of $\mathrm{MD}$ seeds when compared to water control (Figure 6C) underscoring a chemical basis to the inhibition of germination by the elaiosomes. When applied to A. thaliana Col-0 seeds, EE treatment delayed germination rates marked by slower emergence of hypocotyl and shorter radical lengths, when compared to seeds germinated in sterile distilled water (Figure 6D).

\section{DISCUSSION}

The elaiosome accounts for $\sim 5-10 \%$ by weight of the seed and therefore represents an important investment by a plant.
However, investigation of its role in plant success is unclear. Here, we hypothesized that the elaiosome: (i) is critical to seed dispersal by ants, (ii) contains cues that are attractive to myrmecochorous ants, and (iii) composition drives processes to improve plant fitness. The results reported here show support for all these hypotheses. While it is known from previous studies that the elaiosome is of central importance to myrmecochory (Martins et al., 2006), we provide a comprehensive chemical and functional analysis of these lipid-rich appendages across ecotypes. We demonstrate that the elaiosome harbors volatile cues that facilitate dispersal by attracting ants. This makes strategic sense as ants' compound eyes do not provide good resolution and many tropical ants prefer to forage in the dark (Hölldobler, 1978). Ants have the largest number of olfactory receptors in the insect order and commonly use scent trails or olfactory cues for navigation and foraging (Engsontia et al., 2015). Here, ants were attracted to olfactory cues of either diaspores or seeds but did not disperse seeds without elaiosomes. Nonanal and 2-decenal found in this study and shown to be attractive to $P$. grayi ants, could act as long-range cues from elaiosomes allowing ants to locate the diaspores during foraging. In plants, 


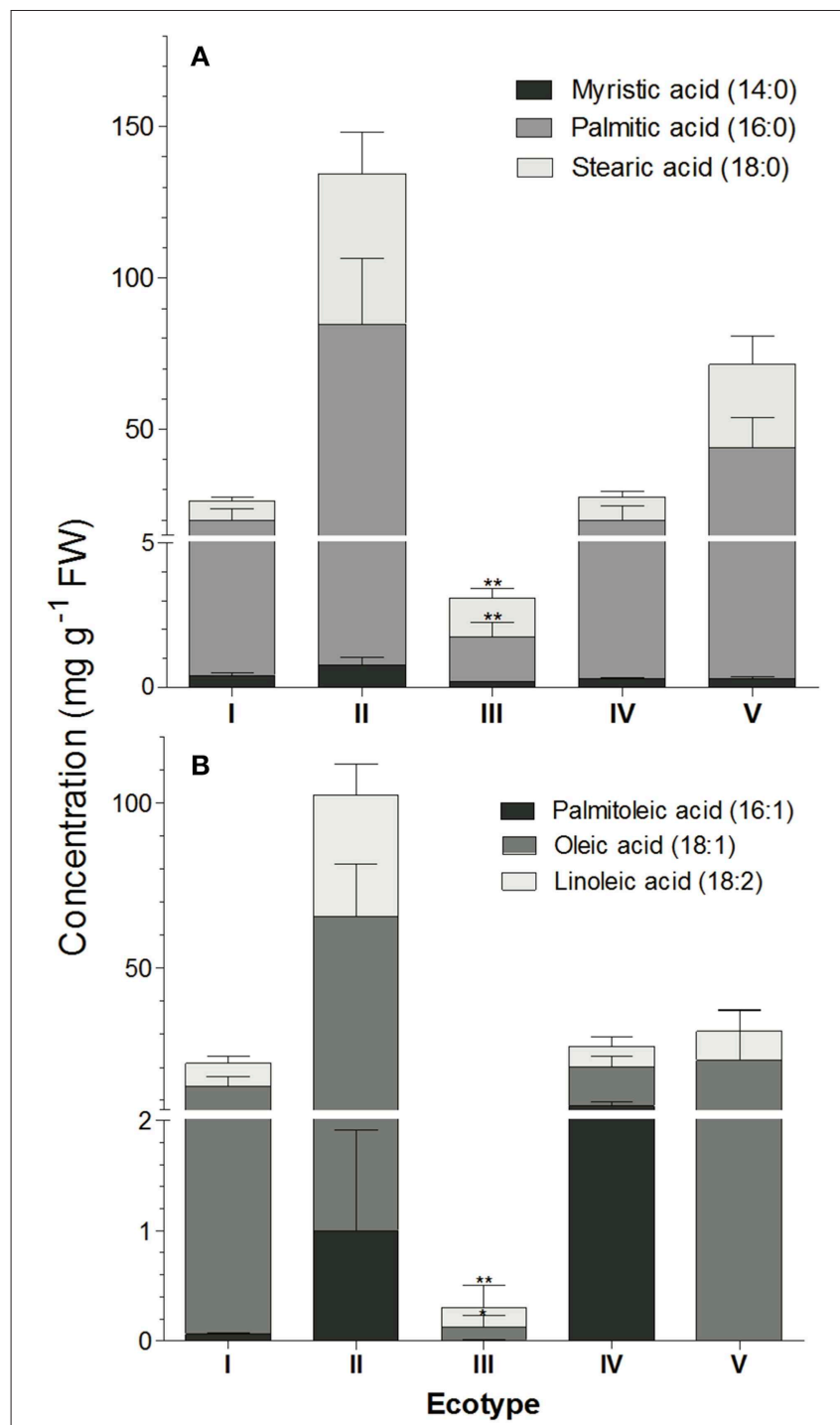

FIGURE 4 | Fatty compositions of $R$. communis elaiosomes. (A) Saturated fatty acids and (B) Unsaturated fatty acids. Data represents mean \pm SE (mg $\mathrm{g}^{-1} \mathrm{FW}$ ) of the fatty acids measured using GCMS analysis. Bonferroni's post-hoc test was done to separate the means after two-way ANOVA. Asterisk indicates points of significant difference between ecotype III and others $(p \leq 0.01, n=4)$.

nonanal is formed by peroxidation of poly-unsaturated fatty acids (PUFAs) and generally acts as priming volatile, protecting them from pathogens by upregulating pathogenesis-related protein 2 (PR2) expression (Heil and Adame-Álvarez, 2010). It is also known to inhibit seed germination and stimulate germination of fungal spores. 2-decenal is formed similarly and is known to have nematicidal activity, particularly against Meloidegyne spp. 2alkenals in particular are activators of transient receptor potential (TRP) channels in sensory neurons, used as defense mechanisms by many arthropods, but also act as specific deterrents against ants (Staples et al., 2002). It is unclear whether these volatiles act as deterrents to non-myrmecochorous ants and/or other predators. Overlap of volatile foraging cues, which may attract

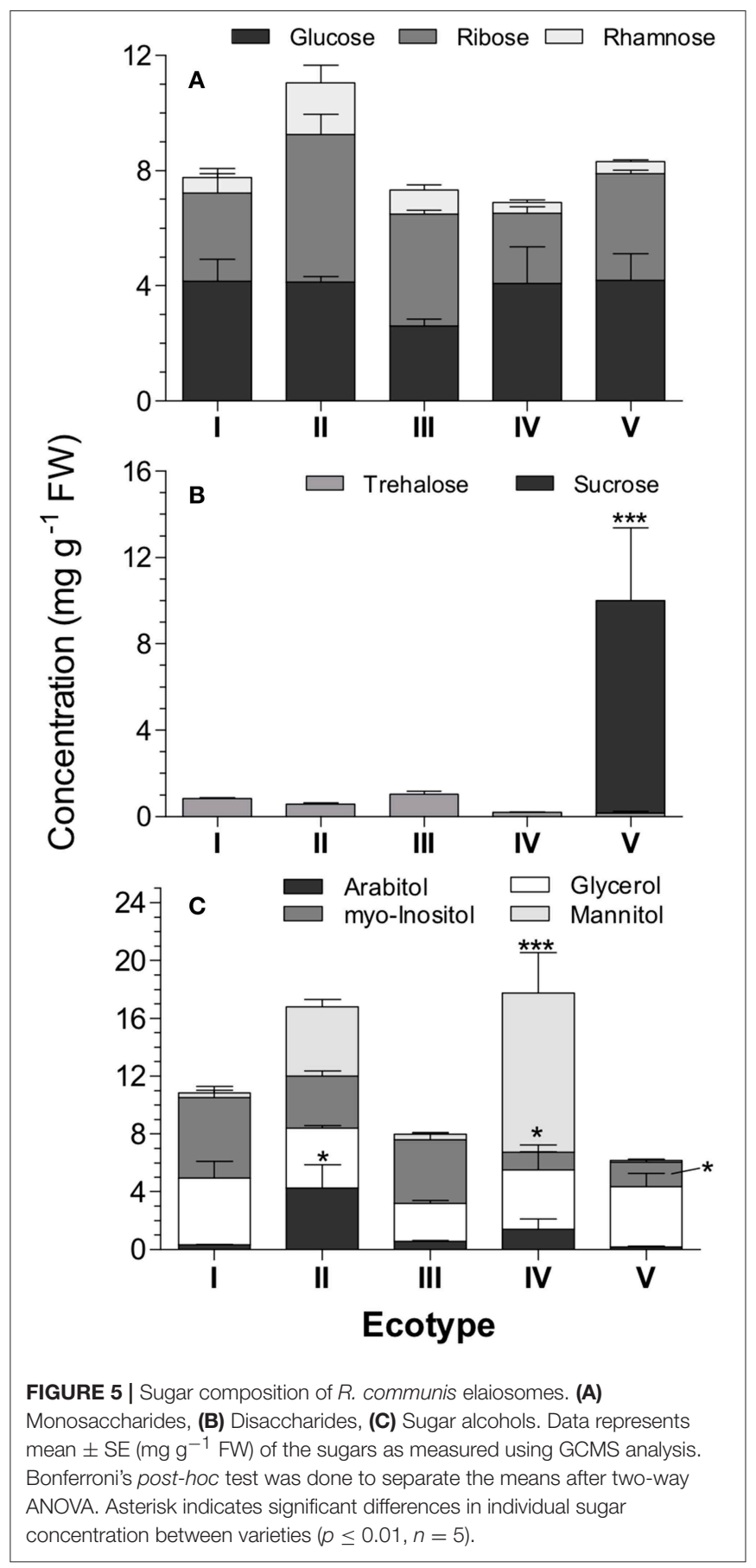

ants over longer distances, with those of seeds and elaiosomes, could allow some ants to hone in onto the seed, before they decide to carry it, determined by other cues present in the elaiosome. Since elaiosomes were independently dispersed and subsequently consumed (Figure 1), an attractive role of seed volatiles could be additive rather than critical to dispersal. This may especially be important for small ants like Pheidole sp. that tend to travel small distances during foraging and collect seeds as food.

We also demonstrate variability in elaiosome compositions across ecotypes and fatty acid composition was found to be 
A

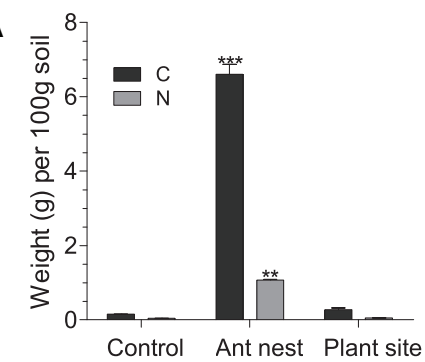

C

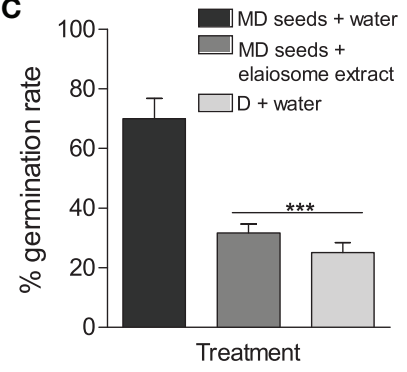

B

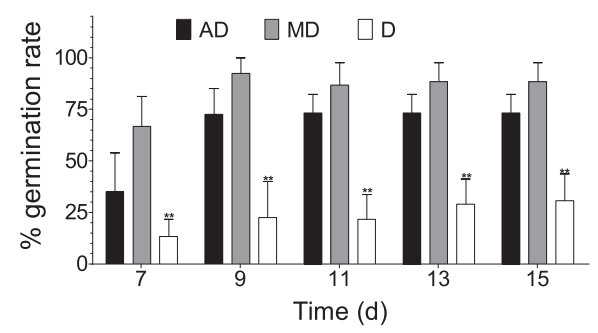

D

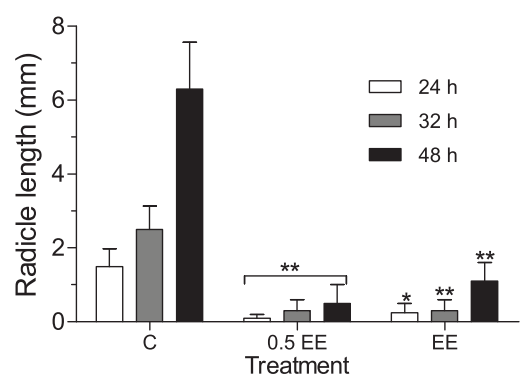

FIGURE 6 | (A) Carbon and nitrogen composition of soil. Data represents mean \pm SE. Bonferroni's post-hoc test was done to separate the means after two-way ANOVA $(p \leq 0.01, n=3)$. (B) Germination assay. Observations were recorded upto 15 days, beyond which no germination was observed. Data represents mean \pm SE of appearance of hypocotyl above the soil. Asterisk indicates significant difference between treatments tested using Tukey's post-hoc test after one-way ANOVA ( $p$ $\leq 0.01, n=3,20$ seeds per treatment) (D, diaspores; AD, ant-detached seeds; MD, mechanically detached seeds). (C) Germination rates after elaiosome extract treatment. Results were taken upto 15 days, beyond which no germination was observed. Data represents mean \pm SE of appearance of hypocotyl above the soil. Tukey's post-hoc test was done to separate the means after one-way ANOVA $(p \leq 0.05, n=6)$ [D, diaspores; MD, mechanically detached seeds; EE, elaiosome extract; C, control (water)]. (D) Germination of Arabidopsis thaliana Col-0 seeds treated with elaiosome extract against half dilution of extract and control (water)-treated seeds. Radicle length $(\mathrm{mm})$ was used as germination index, shown as mean \pm SE. Two-way ANOVA followed by Bonferroni post-tests were used to compare the means of different treatments $(p \leq 0.01, n=10)$ [C, control (water); EE, elaiosome extract].

a key determinant of ant choice in dispersing diaspores, in agreement with previous studies (Hughes et al., 1994; Fischer et al., 2007). We also investigated the sugar composition of the elaiosomes for the first time but, when attractive and unattractive ecotypes were taken as a whole, differences in sugar compositions were not correlated to attractiveness. It is likely that these sugars are present as additional rewards (Heslin et al., 2013), acting as positive selective influences on myrmecochorous ants, driving their fitness and regulating colony structure. They may take the form of extrinsic rewards, which do not act as decisive cues on their own, but are instead motivated by association with intrinsic fatty acid reward cues (Schultz, 2015). The sugar alcohols found in this study could act as lyoprotectants (Adams, 1996) that prevent necrotic death of the elaiosome tissue during dessication.

The role of the elaiosome in promoting plant fitness has been debated for long. According to previous work, elaiosomes play variable roles in individual plant systems, with improved nutrient availability upon dispersal being a common benefit (Trager et al., 2010). Our results showed higher soil nutrients near ant nests and germination inhibition by the elaiosome. Both these clearly highlight the importance of this interaction. Here, the presence of a water-soluble germination inhibitor(s) implies that the inhibitor could, upon water imbibition, come in contact with the germinating embryo. It could also be removed over time under wet conditions, allowing seeds to germinate. Germination inhibitors are naturally present in endosperm, embryo, fruits, or seed coats, imparting dormancy to the seed until the coat is broken and the seed is ready for germination (Evenari, 1949). It is noteworthy that here, the water-soluble factor also inhibits germination of $A$. thaliana seeds indicating that it acts via a universally conserved mechanism. Overall, a germination inhibition process could delay seedling establishment until the diaspore is encountered by a disperser ant. An alternate strategy of fungal breakdown of elaiosome could also help in germination, when ant dispersal is unavailable.

Taken together, this study suggests that diaspores of a parent plant can undergo three distinct fates- (1) seeds transported to ant nests and elaiosome removed, which perform better, (2) elaiosomes removed and seeds remain on site, and (3) elaiosomes unremoved and seeds remains on site. Thus, even diaspores that are not encountered by ants or that have elaiosomes removed on-site can eventually germinate, allowing a population of the progeny to remain undispersed, and decreasing overall competition for ant-dispersal sites (Servigne and Detrain, 2008). This allows enough separation of germinating seeds to avoid competition within a niche during seedling establishment and colonize a wider range of habitats. Our results clearly show that elaiosome chemistry is critical to various processes 
driving myrmecochory within the context of an isolated plant system.

\section{AUTHOR CONTRIBUTIONS}

RV conceived the idea, supervised the experiments, participated in data analysis, and helped draft the manuscript. RS performed the experiments, data analysis, and wrote the manuscript.

\section{FUNDING}

Financial support from NCBS-TIFR, Ramanujan Fellowship (DST-SERB), Department of Biotechnology (DBT) Chemical Ecology Network Grant, SERB Early Career Fellowship

\section{REFERENCES}

Adams, G. D. J. (1996). "Lyophilization of vaccines," in Vaccine Protocols, Vol 4, eds A. Robinson, G. H. Farrar, and C. N. Wiblin (Totowa, NJ: Humana Press), 167-186. doi: 10.1385/0-89603-334-1:167

Bhatkar, A., and Whitcomb, W. H. (1970). Artificial diet for rearing various species of ants. Fla. Entomol. 53:229. doi: 10.2307/3493193

Boieiro, M., Espadaler, X., Gómez, C., and Eustaquio, A. (2012). Spatial variation in the fatty acid composition of elaiosomes in an ant-dispersed plant: differences within and between individuals and populations. Flora 207, 497-502. doi: 10.1016/j.flora.2012.06.007

Crane, P. R., Friis, E. M., and Pedersen, K. R. (1995). The origin and early diversification of angiosperms. Nature 374, 27-33. doi: 10.1038/374027a0

Engsontia, P., Sangket, U., Robertson, H. M., and Satasook, C. (2015). Diversification of the ant odorant receptor gene family and positive selection on candidate cuticular hydrocarbon receptors. BMC Res. Notes. 8, 1-13. doi: 10.1186/s13104-015-1371-x

Evenari, M. (1949). Germination inhibitors. Botan. Rev. 15, 153-194. doi: 10.1007/BF02861721

Fischer, R. C., Richter, A., Hadacek, F., and Mayer, V. (2007). Chemical differences between seeds and elaiosomes indicate an adaptation to nutritional needs of ants. Oecologia 155, 539-547. doi: 10.1007/s00442-007-0931-8

Giladi, I. (2006). Choosing benefits or partners: a review of the evidence for the evolution of myrmecochory. Oikos 112, 481-492. doi: $10.1111 / j .0030-1299.2006 .14258 . x$

Heil, M., and Adame-Álvarez, R. M. (2010). Short signalling distances make plant communication a soliloquy. Biol. Lett. 6, 843-845. doi: 10.1098/rsbl.2010.0440

Heslin, A., Liceaga, L., and Carmona-Galindo, V. D. (2013). Relationship between elaiosome and EFN gland size in castor bean (Ricinus communis L.), an exotic mymercophyte in Southern California. Bios 84, 180-183. doi: 10.1893/0005-3155-84.3.180

Hölldobler, B. (1978). "Ethological aspects of chemical communication in ants," in Advances in the Study of Behavior, Vol. 8, eds J. S. Rosenblatt, R. A. Hinde, C. Beer, and M. C. Busnel (Newark, NJ: Academic Press), 75-115. doi: 10.1016/S0065-3454(08)60132-1

Hughes, L., Westoby, M., and Jurado, E. (1994). Convergence of elaiosomes and insect prey: evidence from ant foraging behaviour and fatty acid composition. Funct. Ecol. 8, 358-365. doi: 10.2307/2389829

Lanza, J., Schmitt, M. A., and Awad, A. B. (1992). Comparative chemistry of elaiosomes of three species of Trillium. J. Chem. Ecol. 18, 209-221. doi: 10.1007/BF00993754

Leal, I. R., Wirth, R., and Tabarelli, M. (2007). Seed dispersal by ants in the semi-arid Caatinga of North-east Brazil. Ann. Bot. 99, 885-894. doi: $10.1093 / \mathrm{aob} / \mathrm{mcm} 017$

Leal, L. C., Lima Neto, M. C., de Oliveira, A. F., Andersen, A. N., and Leal, I. R. (2013). Myrmecochores can target high-quality disperser ants: variation in
(SERB), and Max-Planck Gesellschaft (Partner group program) are acknowledged.

\section{ACKNOWLEDGMENTS}

The authors thank Dr. Ali, UAS, Bengaluru for ant identification; Dr. Chandrashekhara and Dr. Yeshwanth for help in some experimental work. The authors also thank NICE Lab, NCBS for olfactometer setup.

\section{SUPPLEMENTARY MATERIAL}

The Supplementary Material for this article can be found online at: https://www.frontiersin.org/articles/10.3389/fevo. 2019.00246/full\#supplementary-material

elaiosome traits and ant preferences for myrmecochorous Euphorbiaceae in Brazilian Caatinga. Oecologia. 174, 493-500. doi: 10.1007/s00442-013-2789-2

Lengyel, S., Gove, A. D., Latimer, A. M., Majer, J. D., and Dunn, R. R. (2010). Convergent evolution of seed dispersal by ants, and phylogeny and biogeography in flowering plants: a global survey. Perspect. Plant Ecol. Evol. Syst. 12, 43-55. doi: 10.1016/j.ppees.2009.08.001

Martins, V. F., Guimarães, P. R., Silva, R. R., and Semir, J. (2006). Secondary seed dispersal by ants of Ricinus communis (Euphorbiaceae) in the Atlantic forest in Southeastern Brazil: influence on seed germination. Sociobiology 47, 265-274.

Msaakpa, T. S., Obasi, M. O., and Kortse, P. A. (2013). Dormancy breaking and germination of castor (Ricinus Communis L.) seed. J Agric. Biol. Sci. 8, 391-398.

Pfeiffer, M., Huttenlocher, H., and Ayasse, M. (2009). Myrmecochorous plants use chemical mimicry to cheat seed-dispersing ants. Funct. Ecol. 24, 545-555. doi: 10.1111/j.1365-2435.2009.01661.x

Schultz, W. (2015). Neuronal reward and decision Signals: from theories to data Physiol. Rev. 95, 853-951. doi: 10.1152/physrev.00023.2014

Servigne, P., and Detrain, C. (2008). Ant-seed interactions: combined effects of ant and plant species on seed removal patterns. Insectes Soc. 55, 220-230. doi: 10.1007/s00040-008-0991-8

Severino, L. S., Cordoba, O. J., Zanotto, M. D., and Auld, D. L. (2012). The influence of the caruncle on the germination of castor seed under high salinity or low soil water content. Seed Sci. Technol. 40, 139-143. doi: 10.15258/sst.2012.40.1.18

Staples, J. K., Krall, B. S., Bartelt, R. J., and Whitman, D. W. (2002). Chemical defense in the plant bug Lopidae robiniae (Uhler). J. Chem. Ecol. 28, 601-615. doi: 10.1023/A:1014552414580

Trager, M. D., Bhotika, S., Hostetler, J. A., Andrade, G. V., RodriguezCabal, M. A., McKeon, C. S., et al. (2010). Benefits for plants in ant-plant protective mutualisms: a meta-analysis. PLoS ONE. 5:e14308. doi: 10.1371/journal.pone.0014308

Vander Wall, S. B., Kuhn, K. M., and Beck, M. J. (2005). Seed removal, seed predation, and secondary dispersal. Ecology 86, 801-806. doi: 10.1890/ 04-0847

Conflict of Interest Statement: The authors declare that the research was conducted in the absence of any commercial or financial relationships that could be construed as a potential conflict of interest.

Copyright (c) 2019 Sasidharan and Venkatesan. This is an open-access article distributed under the terms of the Creative Commons Attribution License (CC BY). The use, distribution or reproduction in other forums is permitted, provided the original author(s) and the copyright owner(s) are credited and that the original publication in this journal is cited, in accordance with accepted academic practice. No use, distribution or reproduction is permitted which does not comply with these terms. 